\title{
Z J J \\ Penggunaan Peranti Penghubung Antarkalimat dalam Teks Genre Naratif Buku Pelajaran Bahasa Indonesia SMA Kelas XI
}

\author{
Ahmad Sirulhaq ${ }^{1}$ : Mahsun'; Sukri ${ }^{3} ;$ Kaharuddin $^{4}$ \\ 1, 2,3,4Pendidikan Bahasa dan Sastra Indonesia, FKIP Universitas Mataram
}

\section{Posel: ahmad_haq@unram.ac.id}

\begin{abstract}
Abstrak: Dalam pembelajaran kekinian, penekanan dilakukan pada upaya kreatif pemanfaatan bahasa itu sendiri untuk tujuan-tujuan yang lebih praktis. Pandangan ini sering disebut sebagai pembelajaran bahasa berbasis teks. Seiring dengan berubahnya paradigma ini, salah satu kompetensi yang perlu diketahui oleh siswa Sekolah Menengah Atas dalam pembelajaran bahasa Indonesia adalah kemampuan memproduksi teks naratif, sebagaimana tertuang dalam silabus atau kurikulum 2013 (revisi 2017). Kemampuan memproduksi teks naratif itu sendiri tidak lepas dari kemampuan untuk menempatkan konjungsi, baik konjungsi antarkalimat maupun konjungsi antarparagraf. Ketepatan konjungsi antarkalimat maupun antarparagraf ini akan menjamin kekohesian dan kekoherensian paragraf itu sendiri, yang pada akhirnya akan melahirkan sebuah teks naratif yang baik. Akan tetapi, perlu kiranya untuk diperhatikan, apakah penggunaan konjungsi dalam buku pelajaran bahasa Indonesia dalam teks genre naratif sudah lengkap dan tepat atau tidak. Oleh karena itu, makalah ini bertujuan untuk mengelaborasi bentuk-bentuk konjungsi antarkalimat yang digunakan dalam teks genre naratif buku pelajaran bahasa Indonesia SMA Kurikulum 2013 (revisi 2017).
\end{abstract}

Kata Kunci: Peranti Penghubung Antarkalimat, Teks Genre Naratif, Buku Pelajaran, Kurikulum 2013

\section{The Use Of Cohesive Devices Between Sentence in Narrative Genre Text of}

\section{Indonesian Language Learning Book For Xi Class Senior High School}

\begin{abstract}
In contemporary learning, emphasis is placed on creative efforts to use language itself for more practical purposes. This view is often referred to as text-based language learning. As this paradigm changes, one of the competencies that high school students need to know in learning Indonesian is the ability to produce narrative text, as stated in the 2013 syllabus or curriculum (2017 revision). The ability to producenarrative text itself is inseparable from the ability to place conjunctions, both conjunctions between sentences and conjunctions between paragraphs. The accuracy of the conjunctions between sentences and between paragraphs will ensure the cohesion and coherence of the paragraph itself, which in turn will create a good narrative text. However, it is necessary to pay attention to whether the use of conjunctions in Indonesian language textbooks in narrative genre texts is complete and correct or not. Therefore, this paper aims to elaborate the forms of conjunctions between sentences used in the narrative genre text of Senior High School Indonesian language textbooks in 2013 Curriculum (2017 revision).
\end{abstract}

Keywords: Cohesive Devices Between Centence, Narrative Genre Texts, Textbooks, 2013 Curriculum

\section{PENDAHULUAN}

Paradigma pembelajaran bahasa di sekolah, termasuk paradigma pembelajaran Indonesia, mengalami perubahan dari masa ke masa. Bila pembelajaran bahasa pada sampai tahun 90-an lebih banyak bertumpu pada penguasaan gramatika bahasa, pembelajaran bahasa kekinian lebih banyak bertumpu pada upaya kreatif pemanfaatan bahasa itu sendiri 
untuk tujuan-tujuan yang lebih praktis. Misalnya, kemampuan mengomunikasikan pendapat, gagasan, atau pikiran melalui bahasa menjadi salah satu titik tekan pembelajaran bahasa di era kekinian. Pandangan ini sering disebut sebagai pembelajaran bahasa berbasis pada teks (Mahsun, 2014). Salah satu bentuk pembelajaran berbasis pada teks itu adalah pembelajaran produksi berbagai jenis teks, seperti teks genre naratif dan atau teks genre umum atau nonnaratif. Pembuatan cerita, misalnya, adalah salah satu jenis teks yang bergenre naratif.

Seiring dengan berubahnya paradigma ini, salah satu kompetensi yang perlu diketahui oleh siswa sekolah menengah atas dalam pembelajaran bahasa Indonesia adalah kemampuan memproduksi teks naratif, sebagaimana tertuang dalam silabus atau kurikulum 2013. Kemampuan memproduksi teks narasi itu sendiri tidak lepas dari kemampuan untuk menempatkan konjungsi, baik konjungsi antarkalimat maupun konjungsi antarparagraf. Ketepatan konjungsi antarkalimat maupun antarparagraf ini akan menjamin kekohesian dan kekoherensian paragraf itu sendiri, yang pada akhirnya akan melahirkan sebuah teks naratif yang baik.

Tentu, penanda kohesi dan koherensi tidak sendirian menjamin kualitas suatu teks yang diproduksi. Terdapat faktor-faktor lain yang mempengaruhi kualitas suatu teks yang diproduksi, seperti peran semantik, dan lain-lain (Arapoff, 1968). Akan tetapi, ketepatan menempatkan penanda kohesi dan koherensi memiliki peran yang sangat vital dalam menjamin kualitas suatu teks yang akan diproduksi, lebih-lebih dalam produksi teks narasi. Oleh sebab itu, persoalan yang akan diangkat dalam penelitian ini terkait dengan penggunaan konjungsi dalam teks naratif dalam buku pelajaran SMA. Adapun masalah yang akan diangkat dalam makalah ini yaitu bagaimanakah bentuk-bentuk konjungsi antarkalimat yang digunakan dalam teks genre naratif buku pelajaran bahasa Indonesia SMA Kurikulum 2013?

\section{LANDASAN TEORI}

\section{Penelitian yang Relevan}

Penelitian terkait dengan pembelajaran bahasa, terutama yang terkait dengan pelaksanaan Kurikulum 2013 sudah banyak dilakukan oleh para peneliti terdahulu. Di antaranya adalah penelitian yang dilakukan oleh Sirulhaq (2017). Dalam hal ini, Sirulhaq mengkaji tentang konten literasi media dalam pembelajaran bahasa di Sekolah, terintegrasi dalam silabus pembelajaran bahasa Indonesia dalam kurikulum 2013. Dalam hal ini Sirulhaq mengelaborasi sejauh mana konten pembelajaran literasi media di sekolah sudah diterapkan, mulai dari sekolah dasar, menengah, hingga sekolah atas. Berdasarkan kajian yang dilakukan oleh Sirulhaq, terlihat bahwa konten literasi media yang ada di sekolah masih sangat minim. Bahkan di beberapa kelas tertentu, tidak ada sama sekali. Lepas dari itu, apa yang diteliti oleh Sirulhaq tersebut belum menjangkau pembelajaran bahasa berbasis teks.

Penelitian lain yang terkait dengan pembelajaran bahasa Indonesia sekolah adalah penelitian yang dilakukan oleh Lutfiyah, dkk. (2005), Bintari dkk. (2014), Hanafi (2014), Damayanti (2014), dan lain-lain (lihat Mahsun, 2017). Namun, penelitian-penelitian tersebut lebih menekankan pada penerapan metode saintifik dalam pembelajaran bahasa Indonesia di sekolah, dengan memperlihatkan langkah-langkah pembelajaran yang diterapkan dalam metode saintifik. Pada saat yang sama, penelitian-penelitian tersebut belum mengarah pada kajian tentang penerapan pembelajaran bahasa berbasis teks.

Salah satu penelitian penting terkait dengan penerapan metode saintifik, terutama yang terkait dengan pembelajaran bahasa berbasis teks adalah penelitian yang pernah dilakukan oleh Mahsun (2017, bandingkan dengan Idrus, 2017; Zhu, \& Friginal, 2015; Sufanti, 2013; Carrió-Pastor, 2013; Yang, G., Wen, Chen, \& Sutinen, 2012; ). Penelitian ini berupaya untuk mendeskripsikan kemampuan siswa dalam memproduksi teks genre naratif pada siswa kelas IX SMA di Kota Mataram. Berdasarkan hasil penelitian yang dilakukan oleh Mahsun tersebut, terlihat bahwa rata-rata skor yang diperoleh oleh siswa SMA kelas X di Kota Mataram dalam memproduksi teks naratif adalah 60. Artinya, kemampuan memproduksi teks naratif siswa masih sangat kurang.

Yang menarik menjadi titik perhatian dari penelitian yang dilakukan oleh Mahsun tersebut adalah mengenai salah satu indikator produksi teks naratif yang terkait dengan 
penggunaan peranti penghubung antarkalimat. Berdasarkan penelitian ini terlihat bahwa beberapa konjungsi antarkalimat dalam memproduksi teks naratif terlihat sangat dominan berdasarkan jumlah responden dan asal sekolah reponden tersebut. Misalnya, penggunaan peranti penghubung dan hampir merata di setiap responden di semua sekolah (lima SMA yang diteliti), sementara peranti penghubung antarkalimat yang lain bahkan tidak muncul sama sekali, seperti menggunakan kata serta, penggunaan konjungsi pengganti anak kalimat, penggunaan makna dan wujud sinonimi dan hiponimi. Hal ini berarti bahwa kemampuan dalam memproduksi teks naratif pada siswa kelas SMA kelas X masih belum memperlihatkan performa yang baik. Lepas dari itu, maka sangat penting kiranya untuk melihat kembali apakah peranti-peranti penghubung antarkalimat yang ada dalam teks naratif yang ada dalam buku pelajaran SMA berdasarkan Kurikulum 2013 telah sangat memadai atau tidak, pada titik inilah artikel yang penelitian dengan penggunaan konjungsi antarkalimat dalam teks bergenre naratif di buku pelajaran SMA ini ini sangat penting dilakukan.

\section{Relevansi Teoretis}

Pembelajaran bahasa berbasis teks adalah salah satu cara efektif yang bisa ditempuh oleh guru dalam memudahkan penguasaan kompetensi kebahasaan pada siswa yang belajar bahasa, termasuk dalam belajar bahasa (Green, 2005), terutama dalam hal pembelajaran pemerolehan bahasa (Jeong, 2010). Metode ini sudah banyak dilakukan di beberapa negara di dunia, seperti yang dilakukan oleh Yang (2012, bandingkan dengan Partington, 2017; Klimova \& Hubackova, 2014; Visser \& Fuji, 1996). Dalam hal ini, dilakukan eksperimen dengan memanfaatkan teks-teks yang terdapat dalam website sebagai materi pembelajaran. Metode ini diintegrasikan dengan menggunakan teknologi telepon genggam dengan tujuan agar siswa bisa mendapatkan informasi yang penting secara efektif dan efisien dalam website dimaksud.

Teks yang baik harus kohesif dan koheren. Untuk sampai kepada kohesivitas dan koherensivitas tadi, penulis suatu teks membutuhkan penanda-penanda yang dipakai untuk itu, atau apa yang diistilahkan dalam bahasa Inggris sebagai cohesive devices, yaitu "[...] lexical and grammatical structures that support the formulation of coherent Texts (Mortensen, Smith-Lock, \& Nickels, 2009, via Struthers et al, 2013).

Salah satu ciri teks atau paragraf yang baik adalah adanya kohesivitas dan koherensivitas dalam teks itu sendiri. Hal ini agar pembaca mudah memahami teks yang dibaca. Di samping itu, teks yang disusun dengan baik akan mempercepat pembaca dalam membaca teks tersebut, sebagaimana penelitian yang telah dilakukan oleh Ferdosiofour (2015). Dalam penelitiannya, Ferdosiofour memperlihatkan bahwa teks yang ditulis dengan susunan yang baik, salah satunya dengan penanda koherensi, mempercepat waktu pembacaan teks tersebut, walaupun waktu yang dihabiskan oleh masing-masing responden dalam penelitian ini berbeda-beda. Lepas dari itu, kohesivitas teks sangatlah penting untuk diperhatikan dalam penyusunan sebuah teks, termasuk dalam teks bergenre naratif.

Koherensivitas dan atau kohesivitas suatu teks biasanya memiliki penanda kohesi berupa konjungsi walaupun tidak berarti bahwa cara untuk menjamin kohesivitas dan koherensivitas adalah dengan hanya memanfaatkan penanda kohesif kata hubung. Hal ini karena beberapa teks memanfaatkan cara-cara lain dalam menempuh kohesivitas. Walau demikian, sukar untuk memproduksi teks atau wacana yang kohesif dan koheren tanpa melibatkan konjungsi. Misalnya, sebagaimana diperlihatkan oleh (Klimova \& Hubackova, 2014). Dalam hal ini, Klimova \& Hubackova menyebut kohesivitas ini sebagai discourse connecvtivities atau semantics conjuncts.

Dalam bahasa Indonesia kohesivitas biasanya ditandai oleh penanda yang dinamakan sebagai konjungsi. Terdapat banyak penanda konjungsi dalam bahasa Indonesia sebagaimana yang dikemukakan oleh Alwi, dkk. (2003). Konjungsi-konjungsi tersebut biasa digunakan sebagai penghubung antarparagraf, antarkalimat, dan intrakalimat. Di samping itu, bisa juga digunakan untuk menghubungkan antarkalimat yang satu dengan kalimat yang lainnya yang berjauhan tetapi masih dalam satu paragraf. Konjungsi tersebut ada yang bersifat eksplisit, yaitu dengan menggunakan penanda konjungsi, ada juga yang bersifat implisit. Konjungsi yang implisit ini biasanya menggunakan teknik pengulangan bentuk dan pengulangan makna. 


\section{METODE PENELITIAN}

\section{Metode Penjaringan Data}

Wujud data dalam penlelitian ini adalah data kebahasaan yang berupa konjungsi antrakalimat dalam teks bergenre naratif yang terdapat di buku bahasa Indonesia SMA. Karena itu, metode yang digunakan untuk menjaring data dimaksud adalah dengan menggunakan metode dokumentasi. Dalam hal ini peneliti mengambil data-data tersebut dari buku bahasa Indonesia SMA Kelas X bergenre naratif, dengan objek cerita Hikayat Indera Bangsawan dalam kurikulum 2013, revisi 2017. Untuk mendapatkan data yang lebih mendetail, penelitian menggunakan teknik simak dan catat untuk mendokumentasikan bentuk-bentuk konjungsi tersebut (Periksa Mahsun, 2005). Dari sini akan didapatkan datadata penggunaan konjungsi antarkalimat dalam teks bergenre naratif.

\section{Metode Analisis Data}

Mengingat persoalan dalam penelitian ini menyangkut antara lain tentang konjungsi atau peranti penghubung lainnya antarkalimat, maka metode analisis yang akan dipakai dalam peneltian ini yaitu dengan menggunakan metode padan. Sebagai suatu metode, langkah operasional yang lebih konkret dari metode ini yaitu teknik dasar berupa teknik pilah unsur penentu (PUP) (Sudariyanto, 1993). Dalam kaitannya untuk mencapai kerekatan hubungan antarsatuan lingual dalam bahasa Indonesia, misalnya, yang tampak secara linear ke kanan, dapat dibedakan bagian-bagiannya satu sama lainnya. Semua itu dapat diketahui karena daya pilah yang dimiliki oleh peneliti sehingga satuan lingual dalam bahasa tersebut bisa dibedakan. Dalam hal ini satuan lingual dalam bentuk konjungsi antarkalimat.

Sementara untuk membandingkan antarstruktur dalam bahasa Indonesia yang datadatanya telah diperoleh, maka teknik yang dipakai selanjutnya yaitu, teknik lanjutan berupa teknik hubung banding menyamakan (HBS), teknik hubung banding membedakan (HBB), dan teknik hubung banding hal pokok (HBSP) (Sudaryanto, 1993; Mahsun, 2005). Dalam praktik penelitian sesungguhnya, metode padan tersebut berupa hubungan banding antara semua unsur penentu yang relevan dengan semua unsur data yang ditentukan. Karena membandingkan berarti pula mencari persamaan dan perbedaan di antara kedua hal yang dibandingkan; dan karena tujuan akhir ialah mencari hal pokok di antara hal yang dibandingkan, maka kelanjutannya dilakukan dengan membandingkan hal yang pokok.

\section{PEMBAHASAN}

Penghubung antarkalimat tidak harus eksplisit atau tidak harus menggunakan konjungsi yang lazim. Akan tetapi penghubung antarkalimat bisa menggunakan bentukbentuk lain dengan tujuan untuk menghindari penggunaan konjungsi yang berlebihan. Dengan menghindari penggunaan kata-kata penghubung atau konjungsi yang berlebihan, narasi dalam teks akan tampak lebih mengalir dan tidak terkesan monoton. Perhatikan contoh-contoh penggunaan konjungsi atau peranti penghubung dalam teks naratif buku pelajaran SMA kelas X, yang diambil dari teks berjudul Hikayat Indera Bangsawan berikut ini.

\section{Repetisi/Pengulangan Bentuk}

\begin{tabular}{|c|c|c|}
\hline No & Bentuk & Contoh Kalimat \\
\hline 1 & gendang & $\begin{array}{l}\text { (i) Ia naik ke atas mahligai itu dan melihat sebuah gendang } \\
\text { tergantung. Gendang itu dibukanya dan dipukulnya. Tiba-tiba } \\
\text { terdengar ia orang yang melarangnya memukul gendang itu. Lalu } \\
\text { diambilnya pisau dan ditorehnya gendang itu, maka Puteri Ratna } \\
\text { Sari pun keluarlah dari gendng itu. }\end{array}$ \\
\hline 2 & cembul & $\begin{array}{l}\text { Itulah sebabnya ia ditaruh orang tuanya dalam gendang itu } \\
\text { dengan suatu cembul. Di dalam cembul yang lain ialah perkakas } \\
\text { dan dayang-dayngnya. }\end{array}$ \\
\hline 3 & dayang-dayang & $\begin{array}{l}\text { (iii) Di dalam cembul yang lain ialah perkakas dan dayang-dayangnya. } \\
\text { Dengan segera Syah Peri mengeluarkan dayang-dayang itu. } \\
\text { (iv) Tatkala Garuda itu datang Garuda itu dibunuhnya. }\end{array}$ \\
\hline 4 & raksasa & $\begin{array}{l}\text { (v) Ia masuk di sebuah gua yang ada di padang itu dan bertemu } \\
\text { dengan seorang raksasa. Raksasa itu menjadi neneknya dan } \\
\text { menceritakan bahwa Indera Bangsawan sedang berada di negeri }\end{array}$ \\
\hline
\end{tabular}


baginda

7

air susu harimau

8

barang siapa yang dapat menangkap Buraksa itu akan dinikahkan dengan anak perempuannya yang terlalu elok parasnya
Antah Berantah yang diperinah oleh Raja Kabir.

(vi) Beberapa lama di jalan, sampailah ia pada suatu taman, dan bertemu sebuah mahligai. Ia naik ke atas mahligai itu dan melihat sebuah gendang tergantung.

(vii) Maka, anakanda baginda yang dua orang itu pun sampailah usia tujuh tahun dan dititahkan pergi mengaji. [...] Maka baginda pun bimbanglah, tidak tahu siapa yang patut dirayakan dalam negeri karena anaknya kedua orang itu sama-sama gagah.

(viii) Para ahli nujum mengatakan bahwa hanya air susu harimau yang beranak mudalah yang dapat menyembuhkan penyakit itu. Baginda bertitah lagi[,] "Barang siapa yang dapat susu harimau beranak muda, ialah yang akan menjadi suami tuan puteri.

(ix) [...] barang siapa yang dapat menangkap Buraksa itu akan dinikahkan dengan anak perempuannya yang terlalu elok parasnya. [...]"Barang siapa yang dapat susu harimau beranak muda, ialah yang akan menjadi suami tuan puteri.

Dalam tabel di atas terdapat delapan bentuk peranti penghubung antarkalimat berupa repetisi. Di antara bentuk-bentuk tersebut, enam bentuk merupakan kata, seperti gendang, cembul, dayang-dayang, raksasa, mahligai, baginda. Selain itu ada satu repetisi berbentuk frase yaitu air susu harimau dan satu laginya berbentuk klausa yaitu barang siapa yang dapat menangkap Buraksa itu akan dinikahkan dengan akan perempuannya yang terlalu elok parasnya, walaupun repetisinya tidak begitu sempurna.

Yang menarik untuk dibahas lebih jauh dari penggunaan repetisi tersebut adalah bentuk-bentuk kosa kata yang digunakan menggunakan bentuk-bentuk yang berkolokasi satu dengan yang lainnya. Artinya, bentuk-bentuk yang mengalami repetisi tersebut berhubungan erat dengan istilah-istilah kerajaan. Hal ini menunjukan bahwa dalam cerita narasi yang berupa hikayat kerajaan, pemilihan kosa kata-kosa kata tertentu dalam beberapa tempat di dalam teks menciptakan warna sedemikian rupa sehingga peranti antarkalimat tersebut tidak hanya menunjukkan kohesivitas semata, tetapi juga mampu menciptakan kekuatan tema "kerajaan" dalam cerita hikayat yang dimaksud.

\section{Pengulangan Makna dalam Wujud Sinonimi}

\begin{tabular}{|c|c|c|}
\hline No & Bentuk & Contoh Kalimat \\
\hline 1 & $\begin{array}{l}\text { suatu padang yang } \\
\text { terlalu luas; negeri } \\
\text { Antah Berantah }\end{array}$ & $\begin{array}{l}\text { Tersebut pula perkataan Indera Bangsawan pergi mencari } \\
\text { saudaranya. Ia sampai pada suatu padang yang terlalu luas. Ia } \\
\text { masuk ke sebuah gua yang ada di padang itu dan bertemu dengan } \\
\text { seorang raksasa. Raksasa itu menjadi neneknya dan menceritakan } \\
\text { bahwa Indera Bangsawan sedang berada di negeri Antah Berantah } \\
\text { yang diperintah oleh raja Kabir. }\end{array}$ \\
\hline 2 & besi hangat; besi panas & $\begin{array}{l}\text { Indera bangsawan mengatakan susu itu tidak akan dijual dan } \\
\text { hanya akan diberikan kepada orang yang menyediakan pahanya } \\
\text { diselit besi hangat. Maka raja yang Sembilan orang itu } \\
\text { menyingsingkan kakinya untuk diselit Indera Bangsawan dengan } \\
\text { besi panas. }\end{array}$ \\
\hline
\end{tabular}

Pengulangan dalam bentuk sinonim juga bisa dipakai sebagai penanda koherensi atau peranti penghubung antarkalimat. Seperti disebutkan di atas penggunaan bentuk suatu padang yang terlalu luas memiliki kedekatan makna dengan negeri Antah Berantah. Peranti penghubung berupa berupa pengulangan makna dalam bentuk seperti ini membuat paragraf tidak terasa monoton untuk dibaca. Selain itu, penggunaan besi hangat dalam paragraf tersebut disamakan dengan besi panas. Walaupun antara panas dengan hangat memiliki perbedaan, akan tetapi dalam paragraf tersebut, penulis memang hendak mengulang kosakata tersebut dengan maksud ingin menciptakan kesamaan makna. 


\section{Pengulangan Makna dalam Wujud Antonimi}

\begin{tabular}{llrl}
\hline No & \multicolumn{1}{c}{ Bentuk } & \multicolumn{1}{c}{ Contoh Kalimat } \\
\hline 1 & $\begin{array}{l}\text { sakit mata; } \\
\text { menyembuhkannya }\end{array}$ & (i) & $\begin{array}{l}\text { Hatta beberapa lamanya Puteri Kemala Sari pun sakit mata, } \\
\text { terlalu dangat. Para ahli nujum mengatakan bahwa hanya air susu } \\
\text { harimau yang beranak mudalah yang dapat menyembuhkannya. }\end{array}$ \\
$2 \quad \begin{array}{l}\text { hujan pun turunlah } \\
\text { dengan angin rebut; } \\
\text { teduh hujan rebut }\end{array}$ & $\begin{array}{l}\text { (ii) } \\
\text { Maka datang pada suatu hari, hujan pun turunlah dengan angin } \\
\text { rebut, taufan, kalam kabut, gelap gulita, dan tiada kelihatan } \\
\text { barang satu pun. [... Setelah teduh hujan ribut, mereka pun pergi } \\
\text { bercerailah; } \\
\text { mencari }\end{array}$ & saling mencari. & $\begin{array}{l}\text { Maka Syah Peri dan Indera bangsawan pun bercerailah. Setelah } \\
\text { teduh hujan rebut, mereka pun pergi saling mencari. }\end{array}$ \\
\hline
\end{tabular}

Antonim adalah lawan kata, baik bentuk maupun maknanya. Dalam paragraf, penggunaan antonim dalam satu paragraf yang sama berarti hal tersebut dimaksudkan agar agar tema pembicaraan tetap fokus pada satu ide karena bagaimana pun satu paragraf harus memiliki satu ide pokok. Cara agar ide pokok itu tidak melebar maka perlu dibuatkan peranti penghubung antarkalimat yang dalam satu paragraf tersebut tetap berhubungan satu sama lainnya. Dalam hal ini, penulis menggunakan penanda penghubung antarkalimat dengan membuat lawan kata antara sakit mata dan menyembuhkannya; hujan pun turunlah dengan angin ribut dan teduh hujan rebut; bercerailah dan saling mencari.

\section{Pengulangan Makna dalam Wujud Hiponimi}

\begin{tabular}{|c|c|c|c|}
\hline No & Bentuk & & Contoh Kalimat \\
\hline 1 & raja; kerajaan & (i) & $\begin{array}{l}\text { Tersebutlah perkataan seorang raja yang bernama Indra Bungsu } \\
\text { dari Negeri Kobat Syahrial. Setelah beberapa lama di atas kerajaan, } \\
\text { tiada juga beroleh putera. }\end{array}$ \\
\hline 2 & $\begin{array}{l}\text { ngaji; kitab usul, fikih, } \\
\text { hingga saraf, tafsir }\end{array}$ & (ii) & $\begin{array}{l}\text { Maka anakanda baginda yang dua itu pun sampailah usia tujuh } \\
\text { tahun dan dititahkan pergi mengaji kepada Mualim Sufian. } \\
\text { Sesudah tahu mengaji, mereka dititah pula mengaji kitab usul, } \\
\text { fikih, hingga saraf, tafsir sekaliannya diketahuinya. }\end{array}$ \\
\hline 4 & takluk; upeti & (iii) & $\begin{array}{l}\text { Adapun Raja Kabir itu takluk kepada Buraksa dan akan } \\
\text { menyerahkan puterinya, Puteri Kemala Sari sebagai upeti. }\end{array}$ \\
\hline 5 & $\begin{array}{l}\text { sakit mata; air susu } \\
\text { harimau }\end{array}$ & (iv) & $\begin{array}{l}\text { Hatta beberpa lamanya Puteri Kemala Sari pun sakit mata, terlalu } \\
\text { dangat. Para ahli nujum mengatakan bahwa hanya air susu } \\
\text { harimau yang beranak mudalah yang dapat menyembuhkannya. }\end{array}$ \\
\hline 6 & $\begin{array}{l}\text { elok parasnya; tuan } \\
\text { puteri }\end{array}$ & (v) & $\begin{array}{l}\text { [...] barang siapa yang dapat menangkap Buraksa itu akan } \\
\text { dinikahkan dengan akan perempuannya yang terlalu elok } \\
\text { parasnya. [...]"Barang siapa yang dapat susu harimau beranak } \\
\text { muda, ialah yang akan menjadi suami tuan puteri. }\end{array}$ \\
\hline
\end{tabular}

Penggunaan penanda kohesi antarkalimat juga sering menggunakan bentuk hiponimi. Maksudnya ialah penggantian antara bentuk umum dan bentuk khusus, yang satu bersifat umum dan yang lain bersifat khusus, yang satu menjadi ordinat dan yang lain menjadi subordinat. Contoh penggunaan hiponimi dalam teks naratif Hikayat Indera Bangsawan cukup variatif, misalnya hubungan antara kerajaan dan raja, mengaji dan kitabusul, takluk dan upeti, sakit mata (penyakit) dan air susu harimau (obat), tuan puteri dan elokparasnya.

\section{Pengulangan Makna dalam Wujud Anafora}

\begin{tabular}{lll}
\hline No & \multicolumn{1}{c}{ Bentuk } & \multicolumn{1}{c}{ Contoh Kalimat } \\
\hline 1 & Indera Bungsu; ia & (i) $\begin{array}{l}\text { Tersebutlah perkatan seorang raja yang bernama Indra Bungsu } \\
\text { dari Negeri Kobat Syahrial. [...] Maka pada suatu hari, ia pun } \\
\text { menyuruh orang membaca qunut dan sedekah kepada fakir miskin. }\end{array}$ \\
$2 \quad \begin{array}{l}\text { Baginda yang dua itu; } \\
\text { mereka; -nya }\end{array}$ & (ii) $\begin{array}{l}\text { Maka anakanda baginda yang dua itu pun sampailah usia tujuh } \\
\text { tahun dan dititahkan pergi mengaji kepada Mualim Sufian. } \\
\text { Sesudah tahu mengaji, mereka dititah pula mengaji kitab usul, } \\
\text { fikih, hingga saraf, tafsir sekaliannya diketahuinya. }\end{array}$
\end{tabular}


Anafora adalah salah satu bentuk penanda kohesi antarkalimat dalam suatu paragraf yang sering digunakan oleh penulis dalam teks naratif. Anafora ini biasanya ditandai dengan bentuk bentuk seperti, ia, dia, mereka, -nya. Dalam teks naratif bentuk-bentuk tersebut biasanya menggunakan anafora berupa kata ganti persona orang ketiga, baik jamak atau tunggal. Begitu juga dalam cerita Hikayat Indera Bangsawan terlihat anafora ia, mereka, dan -nya.

\section{Penggunaan Konjungsi/Kata Hubung}

\begin{tabular}{|c|c|c|}
\hline No & Bentuk & Contoh Kalimat \\
\hline 1 & setelah & [...] Setelah beberapa lama di atas kerajaan, tiada jug beroleh putra. \\
\hline 2 & maka & $\begin{array}{l}\text { Maka pada suatu hari, ia pun menyuruh orang membaca qunut dan } \\
\text { sedekah kepada fakir miskin. }\end{array}$ \\
\hline 3 & hatta & $\begin{array}{l}\text { (iii) Hatta beberapa lamanya, Tuan Puteri Sitti Kendi pun hamillah dan } \\
\text { bersalin dua orang putra laki-laki. }\end{array}$ \\
\hline 4 & lalu & Lalu diambilnya pisau dan ditorehnya gendang itu. \\
\hline 5 & itulah & $\begin{array}{l}\text { Itulah sebabnya ia ditaruh orang tuanya dalam gendang itu dengan } \\
\text { suatu cembul. }\end{array}$ \\
\hline 6 & demikian . & Kalau tidak demikian, negeri itu akan dibinasakan oleh Buraksa. \\
\hline 7 & sementara itu & $\begin{array}{l}\text { (vii) Sementara itu Indera Bangsawan sudah mendapat susu harimau } \\
\text { dari raksasa (neneknya) dan menunjukkan kepada raja. }\end{array}$ \\
\hline 8 & adapun & (viii) Adapun setelah Tuan Puteri sembuh, baginda tetap bersedih. \\
\hline
\end{tabular}

Dalam teks naratif penanda kohesivitas sering menggunakan kata hubung, termasuk kata hubung antarkalimat. Hal ini digunakan agar antara kalimat yang satu dengan kalimat yang lainnya memiliki keterhubungan yang erat. Bahkan, kata hubung antarkalimat ini tidak harus berdekatan satu sama lainnya, bentuk itu bisa berada pada kalimat yang berjauhan, tetapi masih dalam satu paragraf yang sama. Hal ini dilakukan untuk mencapai koherensi yang bagus dan tidak terdengar monoton. Dalam cerita Hikayat Indera Bangsawan, penggunaan konjungsi pun banyak digunakan, seperti: setelah, hatta, sesudah, jikalau, beberapa lama dijalan, lalu, itulah, demikian, sementara itu, dan adapun.

\section{PENUTUP}

Dalam pembelajaran bahasa berbasis teks, penekanan pada penciptaan teks kepada siswa merupakan tututan yang harus dipenuhi. Akan tetapi, ditemukannya kelemahan dalam produksi teks oleh sisiwa sedikit banyak karena faktor kurangnya pemahaman siswa terhadap penggunaan peranti-peranti penghubung di dalam produksi teks itu sendiri, termasuk dalam produksi teks naratif. Oleh karena itu, dalam pembelajaran berbasis teks di sekolah, guru sebaiknya menggunakan teks-teks yang sudah tersedia dalam buku paket yang ada agar siswa lebih mudah mengingat dan menyerap pelajaran yang diberikan. Salah satunya dengan memanfaatkan teks naratif Hikayat Indera Bangsawan karena di dalamnya sudah terdapat unsur-unsur penanda atau peranti penghubung antarkalimat yang sudah lengkap dan variatif.

\section{DAFTAR PUSTAKA}

Alwi, dkk. (2014). Tata Bahasa Baku Bahasa Indonesia Edisi Kesembilan. Jakarta: Balai Pustaka.

Arapoff, N. (1968). The semantic role of sentence connectors in extra-sentence logical relationships. Tesol Quarterly, 2(4), 243-252.

Carrió-Pastor, M. L. (2013). A contrastive study of the variation of sentence connectors in academic English. Journal of English for Academic Purposes, 12(3), 192-202.

Ferdosipour, A. (2015). The Effect of Scientific-text Coherency Assisted by Paragraph Regarding the Reader's Performing Speed. Procedia-Social and Behavioral Sciences, 190, 533-538.

Ferdosipour, A. (2015). The Effectiveness of cohesion of science text by means of the paragraph on attitude. Procedia-Social and Behavioral Sciences, 190, 523-528. 
Green, J. (2005). Replacing lectures in conventional university courses by text-based flexible learning can be a rewarding experience for the lecturer and students. Biochemistry and Molecular Biology Education, 33(3), 205-207.

Isodarus, P. B. (2017). Pembelajaran Bahasa Indonesia Berbasis Teks. Sintesis, 11(1), 1-11.

Jeong, H., Sugiura, M., Sassa, Y., Wakusawa, K., Horie, K., Sato, S., \& Kawashima, R. (2010). Learning second language vocabulary: neural dissociation of situation-based learning and text-based learning. Neuroimage, 50(2), 802-809.

Klimova, B. F., \& Hubackova, S. (2014). Grammatical Cohesion in Abstracts. Procedia-Social and Behavioral Sciences, 116, 664-668.

Mahsun, M. S. (2005). Metode Penelitian Bahasa: Tahapan Strategi, Metode dan Tekniknya. PT RajaGrafindo Persada.

Mahsun (2014). Teks dalam Pembelajaran Bahasa Indonesia Kurikulum 2013. Jakarta: Rajawali Press.

Partington, A. (2017). Evaluative clash, evaluative cohesion and how we actually read evaluation in texts. Journal of Pragmatics, 117, 190-203.

Struthers, L., Lapadat, J. C., \& MacMillan, P. D. (2013). Assessing cohesion in children's writing: Development of a checklist. Assessing Writing, 18(3), 187-201.

Sirulhaq, Ahmad. (2017). Media Literacy and Educational Curriculum: Reviewing Bahasa Indonesia Subject In the "Curriculum 2013". Prosiding Asean Education Simposium.

Sudaryanto. (1993). Metode dan Aneka Teknik Analisis Bahasa: Pengantar Penelitian Wahana Kebudayaan Secara Linguistis. Duta Wacana University Press.

Sufanti, M. (2013). Pembelajaran Bahasa Indonesia Berbasis Teks: Belajar dari Ohio Amerika Serikat. PBSID FKIP UMS. http:/publikasiilmiah. ums. ac. id/bitstream/handle/123456789.(Diunduh pada 28 September 2014).

Suherli, dkk. (2017). Buku Bahasa Indonesia Kelas X. Kementrian Pendidikan dan Kebudayaan Republik Indonesia.

Visser, E. M., \& Fuji, M. (1996, August). Using sentence connectors for evaluating MT output. In Proceedings of the 16th conference on Computational linguistics-Volume2 (pp. 1066 1069). Association for Computational Linguistics.

Yang, G., Sutinen, E., \& Wen, D. (2012, July). Chunking and Extracting Text Content for Mobile Learning: A Query-focused Summarizer Based on Relevance Language Model. In Advanced Learning Technologies (ICALT), 2012 IEEE 12th International Conference on (pp. 126-128). IEEE.

Yang, G., Wen, D., Chen, N. S., \& Sutinen, E. (2012, July). Personalized text content summarizer for mobile learning: An automatic text summarization system with relevance based language model. In Technology for Education (T4E), 2012 IEEE Fourth International Conference on (pp. 90-97). IEEE.

Zhu, Y., \& Friginal, E. (2015, March). Interactive Visual Text Analysis for Corpus-Based Language Learning. In Big Data Computing Service and Applications (BigDataService), 2015 IEEE First International Conference on (pp. 462-467). IEEE. 